\title{
Autofluorescence bronchoscopy and lung cancer diagnosis
}

Camelia Bădescu*, Florin Mihălțan

Camelia Badescu - Bronchial Endoscopy Department, Florin Mihaltan - Pneumology III, Pneumology Institute, "Marius Nasta" Bucharest

\begin{abstract}
English:

Lung cancer (LC), is a disease who has increasing prevalence, with a major impact to morbidity and mortality but also significant consumption of resources. The incidence of $L C$ cases is in progression and early diagnosis becomes extremely important in increasing the quality of life and survival. Detection of preneoplastic mucosal lesions can be performed with autofluorescence bronchoscopy (AF). This is not a new method of diagnosis being still in research for standardization and an applicability as easy as possible. AF should be used as a screening method in pacients with suspected LC.
\end{abstract}

Keywords

lung cancer $•$ preneoplastic lesions $\bullet$ autofluorescence bronchoscopy $\bullet$ screening

\section{Bronhoscopia cu autofluorescenta si diagnosticul de neoplasm bronho-pulmonar}

Rezumat

Romanian:

Neoplasmul bronho-pulmonar (NBP) este o afectiune care are prevalenta in crestere, cu impact major asupra morbiditatii si mortalitatii dar si consum important de resurse. Incidenta cazurilor de NBP este in ascensiune si diagnosticul precoce devine extrem de important in cresterea calitatii vietii si supravietuirii. Detectia leziunilor preneoplazice de mucoasa se poate efectua cu ajutorul bronhoscopiei cu autofluorescenta (AF). Aceasta nu este o metoda noua de diagnostic, fiind inca in cercetare pentru standardizare si o aplicabilitate cat mai facila. AF ar trebui folosita ca metoda de screening la pacientii cu suspiciune de NBP.

Cuvinte-cheie

neoplasm bronho-pulmonar $\bullet$ leziuni preneoplazice $\bullet$ bronhoscopie cu autofluorescenta $\bullet$ screening

Lung cancer (LC) is the second most common cancer, after prostate cancer in men and breast cancer in women (1), with a relatively high incidence in men (2). This is the most important cause of death worldwide, exceed mortality of breast, prostate, colorectal and leukemia in specific age groups and for both sexes (3). Despite progress in disease prevention, mortality due to secondary LC remains between $5 \%$ and $17 \%$ and depends on the stage of disease in diagnosis time (4).

The most important risk factor in this cancer remains the smoke, but a lot of studies have revealed many causes: familial history of LC, asbestos exposure, aromatic hydrocarbons, heavy metals and radon (5). Long-term effects of electronic cigarette use recognise little details but mice exposure at this type of cigarette goes to lung adenocarcinoma (ADK) (6).

Early diagnosis of LC remains a wish. The most important method for the noninvasive diagnosis of LC is bronchoscopy. This contributes to histopathological diagnosis and staging of the disease. A high precision method in early diagnosis of viewing safety margins or the extent of the disease and which has fully proved its usefulness in the last two decades remains autofluorescence (AF) bronchoscopy. This can detect minimal mucosa lesions, which can be not visualised in standard light (7).

AF bronchoscope uses a special light (blue), with a wavelength between $380 \mathrm{~nm}$ and 440 nanometres (nm) to identify preneoplastic lesions. The AF phenomenon is based on the property of intracellular compounds to reflect the light when are specifically stimulated. They are specifically called fluorophores and they are in high quantity in normal tissue (collagen, tryptophan, elastin and porphyrins) (8). As preneoplastic changes appear, the amount of these compounds in the studied territory decreases. Normal mucosa will have a green phosphorescent and modified mucosa will include shades of red-brown and fuchsia. The flexible bronchoscope is equipped with both lights (standard and blue) which are used by manual switching depending on the explorer's decision (9). 
Mucosal changes involve several degrees of evolution and have been classified into low-grade (mild and moderate) high-grade dysplasias (severe and in situ carcinoma) and invasive carcinoma. The evolution of these lesions to LC is variable (10). Their regression occurs in a high proportion for mild and moderate dysplasia, while, much more frequently, high-grade lesions will undergo transformations in the sense of irreversible changes to invasive carcinoma, and the time elapsed from the appearance of the first preneoplastic lesions to their transformation in neoplasia varies from 8 years to 15 years (11). The more advanced the preneoplastic lesions, the greater the risk of its transformation into higher grade lesions so that severe dysplasia will progress in $41 \%$ of cases and will regress in $59 \%$ of cases, and carcinoma in situ will become malignant in $87 \%$ from cases while in only $13 \%$ of cases the lesions regress spontaneously (12).

The disadvantage of AF bronchoscopy is low specificity, only to the extent of $65 \%$. Unspecific inflammatory or granulomatous lesions, the trauma of mucosa including recent biopsy can lead to false-positive result. This can be remedied by the concomitant use, within the same bronchoscope, of both types of light with an increase of specificity up to $71-80 \%$ (13).

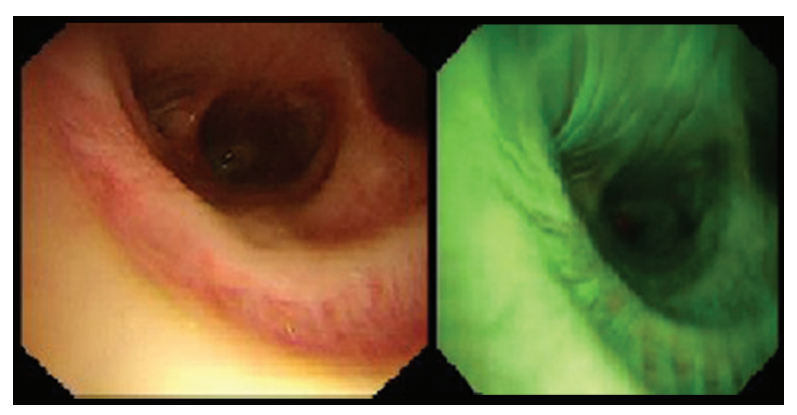

Archive Prof. Dr. Ulmeanu Ruxandra

Normal aspects of tracheobronchial mucosa

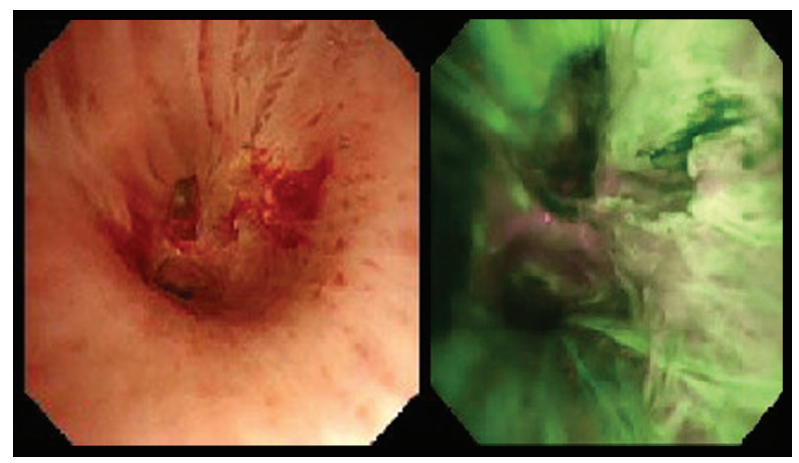

Archive Prof. Dr. Ulmeanu Ruxandra

Pathological aspects of tracheobronchial mucosa

\section{Material and method}

This article contains data from a prospective study conducted in Marius Nasta' Institute in outpatient department which had as main objective the early detection of neoplastic lesions of the bronchial mucosa by using AF bronchoscopy. It includes patients' naive for bronchoscopy or with previous nondiagnostic bronchoscopies for malignancy. The group consisted of 156 patients, selected in the period 2016-2018, with radiological suspicion of broncho-pulmonary neoplasm. Patients are introduced in the study after completing the questionnaire by the attending physician, where demographic data are noted along with relevant details on health status, comorbidities or other important results.

\section{Inclusion criteria}

Aged over 18 years, informed consent was signed with high radiological suspicion of LC.

\section{Exclusion criteria}

Aged under 18 years, patients who refuse bronchoscopy or health status make it impossible to perform bronchoscopy.

\section{Evaluation protocol}

\section{Mandatory investigation}

Respiratory functional evaluation (spirometry and complex functional tests), pulmonary imaging evaluation (cardiopulmonary X-Ray, or better-computed tomography) subsequently completed with brain and abdominal scanning for final staging, cardiologic examination, EKG, usual blood tests and specific to each pathology.

Before bronchoscopy, the attending physician completes a table in which are listed all the patient's ailments and the current treatment, checking also the performance of prebronchoscopy procedures.

The preliminary discussion about bronchoscopy was performed at the salon, together with the attending physician. The bronchologist describes to the patient in detail the anaesthesia, bronchoscopy and the monitoring period after bronchoscopy.

\section{Performing bronchoscopy}

Both white light (WL) and AF bronchoscopy were performed in the same session, by manually switching the light source with real-time visualisation in both standard and blue light, noting mucosal changes and taking necessary samples (biopsy, brushing and bronchial lavage). The endobronchial examination was performed after ensuring the permeability of the airways and using a disposable mouthpiece to ensure the integrity of the bronchoscope. 
Gold-standard for confirmation of neoplasia by bronchoscopy remain biopsy and perform histopathological examination with a positive diagnosis rate in $82 \%$ of cases. When a biopsy is combined with brushing and bronchoalveolar lavage, the detection rate increases up to $87 \%$ (14). The changes of mucosa in $\mathrm{WL}$ and AF were represented by any abnormal aspect of it (oedema, congestion, hypervascularisation) and red-brown colour in blue light.

The samples were collected with disposable materials, respecting the norms and standards in force.

During bronchoscopy, peripheral blood saturation in $\mathrm{O} 2$ and heart rate were monitoring using a periodically calibrated pulse oximeter.

\section{Statistical analysis}

Statistical data processing was performed using the IBM SPSS Statistics Subscription programme, version 1.0.0.1406.

- The group includes 156 patients of which: 73 (46.8\%) females and $83(53.2 \%)$ males - Figure 1.

- The age of the patients varied between 33 years and 85 years, with an average of 62.15 , with a higher frequency for the 60-70 age group - Figure 2.

- LC frequency increases with age, up to 70 years. If in the age range $30-39$ the incidence of LC is only $1.9 \%$ $(n-3)$, for the next decade of age, the increase in almost $1 \%(2.5 \%, n-4)$, for the decades $50-59$ and $60-69$, it increases considerably $(12.1 \%, n-12$ respectively $23.7 \%$, $n-37$ ), after de age of 70 , the incidence seems to be declining $(7.6 \%, n-12$ for decade $70-79$ and $1.9 \%, n-3$ for decade 80-89). Figure 3.

- The highest frequency of neoplasms was recorded in the age range $50-59(44.7 \%, n-17)$, followed by the range 60-69 (41.5\%, $n-27)$ and $70-79(24.3 \%, n-9)$ The histopathological types that appear with the highest share are squamous and ADK. Dysplasias were diagnosed in the age ranges $50-59$ and $60-69$. Thus, both preneoplastic changes and neoplasms occur more frequently between 50 years and 70 years, with a decrease in incidence after this age.

- All patients included in the study underwent both WL and AF bronchoscopy. More than half of them had mucosal changes (oedema, congestion, hypervascularisation), suspected neoplastic or even patent infiltration, in AF $53.8 \%(n-84)$ Figure 5 , significantly more than in $\mathrm{WL}$ $37.8 \%(n-59)$ Figure 4.

- How mucosal changes were more common in AF than examination in WL (by 16\%), the degree of tumour confirmation was lower in patients examined in $\mathrm{WL}$ $(26.3 \%, n-41)$, compared to those examined in $\mathrm{AF}$ $(33.3 \%, n-52)$ - Figure 6 . This is essential for the study because patients without visible mucosal changes in WL had minimal mucosal changes in blue light and harvested biopsies diagnosed early neoplasia for patients who would be re-evaluated later and at which the therapeutic decision would have been delayed. Thus, the appearance of the mucosa when examined in AF, raises the suspicion of a local preneoplastic process, which requires further investigation.

Thus, an apparently normal mucosa in WL appears suspiciously infiltrative in AF in $16 \%(n-25)$ of the total cases included in the study, which is consistent with the results of studies published so far (15).

The sensitivity and specificity of the examination in blue light versus WL are statistically significant and range from 0.777 to 0.916 and 0.705 to 0.855 , respectively. Figures 7 and 8 .

Increasing the specificity of the method, by combined examination in both lights, leads to the identification of several patients with mucosal changes - suspected of neoplasia.
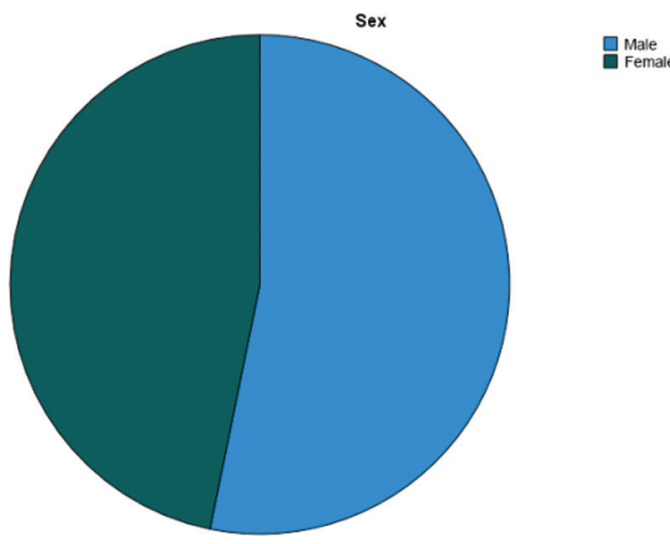

Figure 1. Gender distribution of patients.

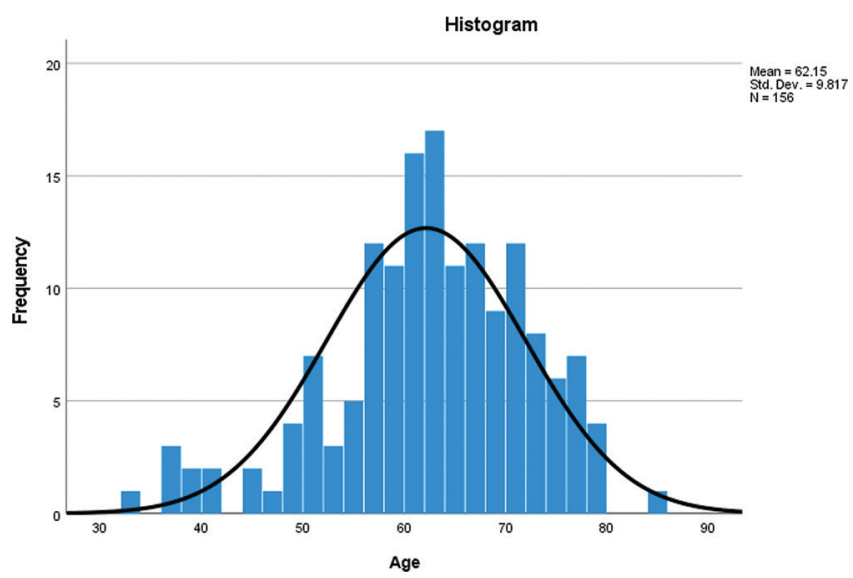

Figure 2. Age distribution of the patient group. 


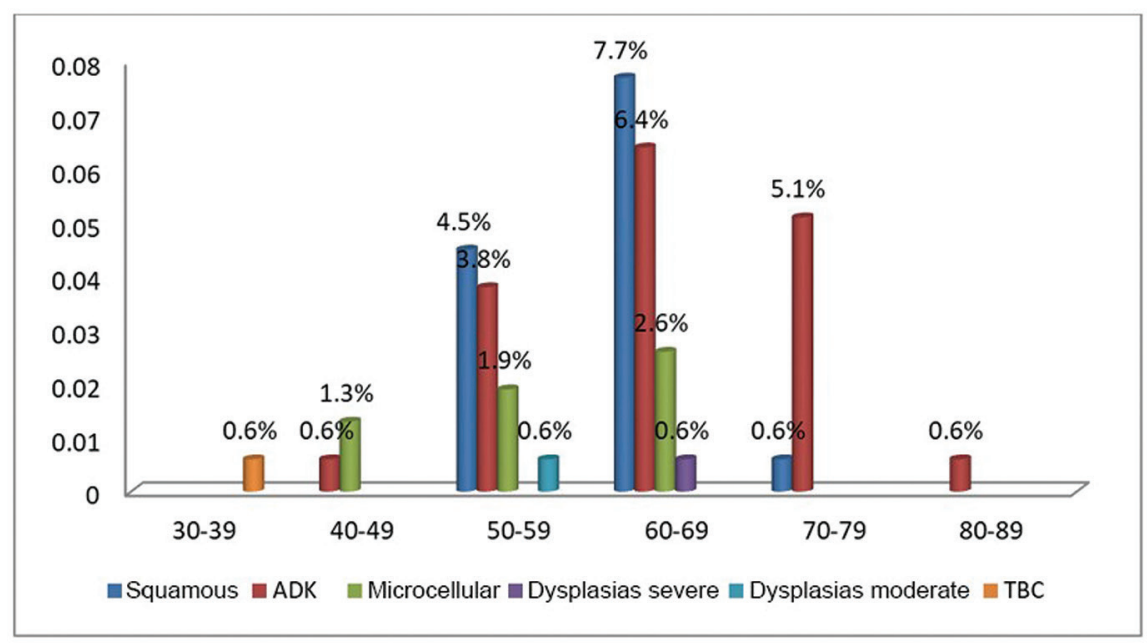

Figure 3. Distribution of histological types by age groups.
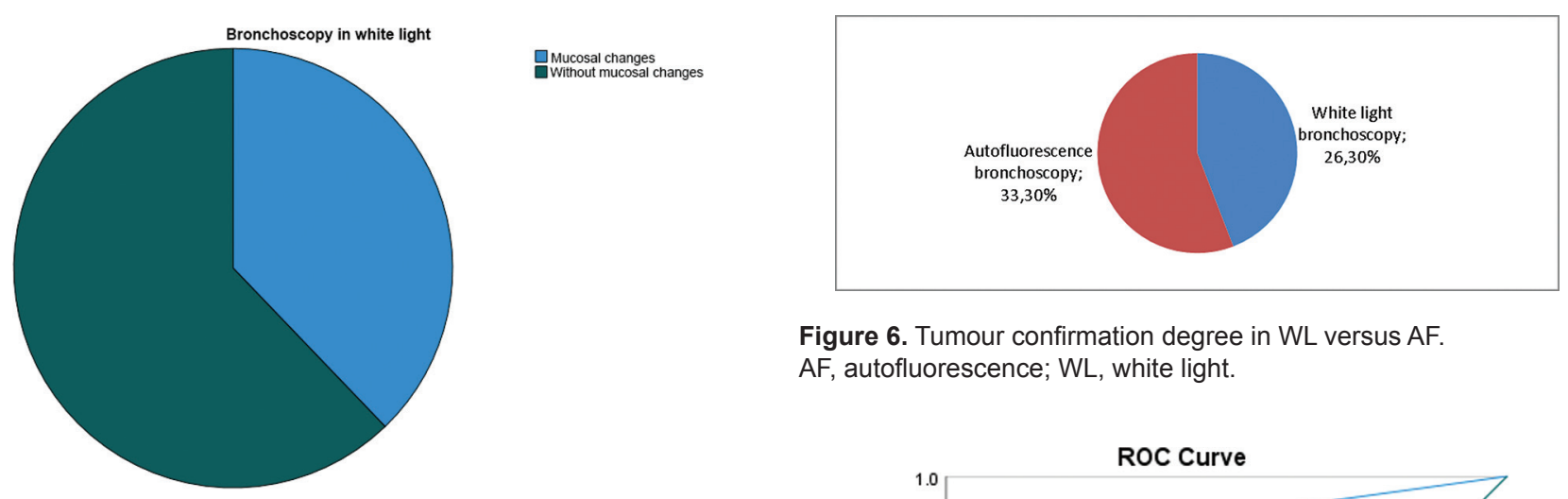

Figure 6. Tumour confirmation degree in $\mathrm{WL}$ versus AF. $A F$, autofluorescence; WL, white light.

Figure 4. Mucosal changes in WL bronchoscopy. WL, white light.

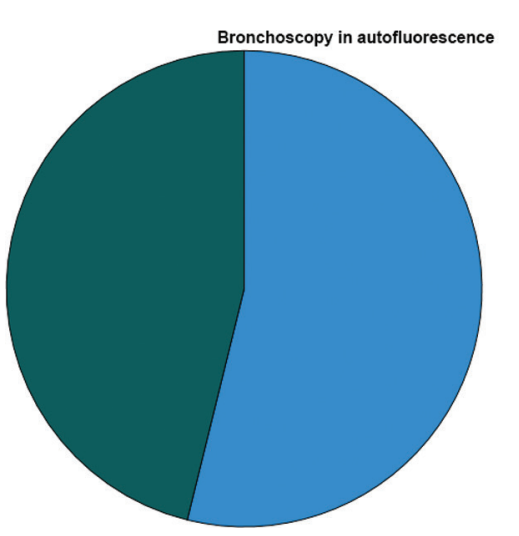

Figure 5. Mucosal changes in AF bronchoscopy. AF, autofluorescence.

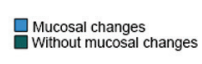
$\mathrm{AF}$, autofluorescence.

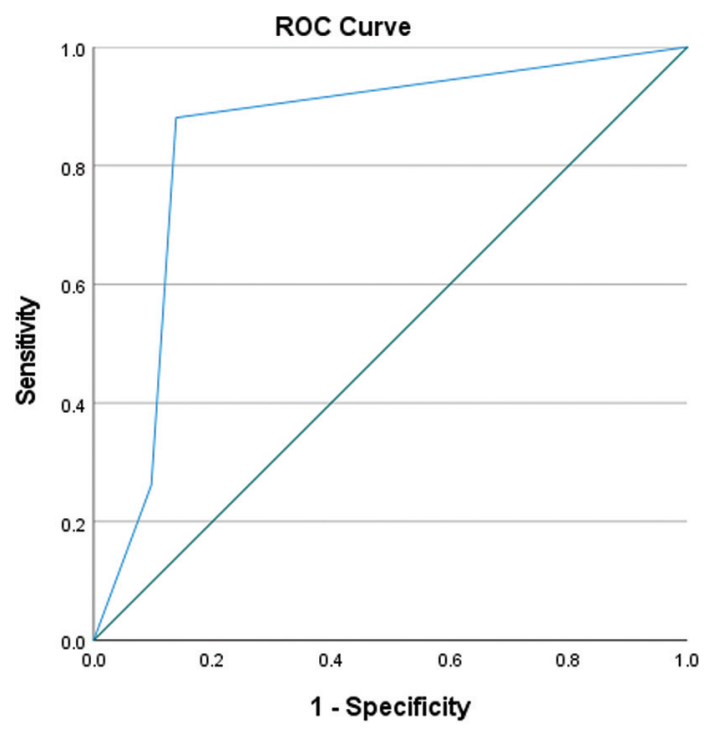

Diagonal segments are produced by ties.

Figure 7. Sensibility and specificity for AF bronchoscopy. 


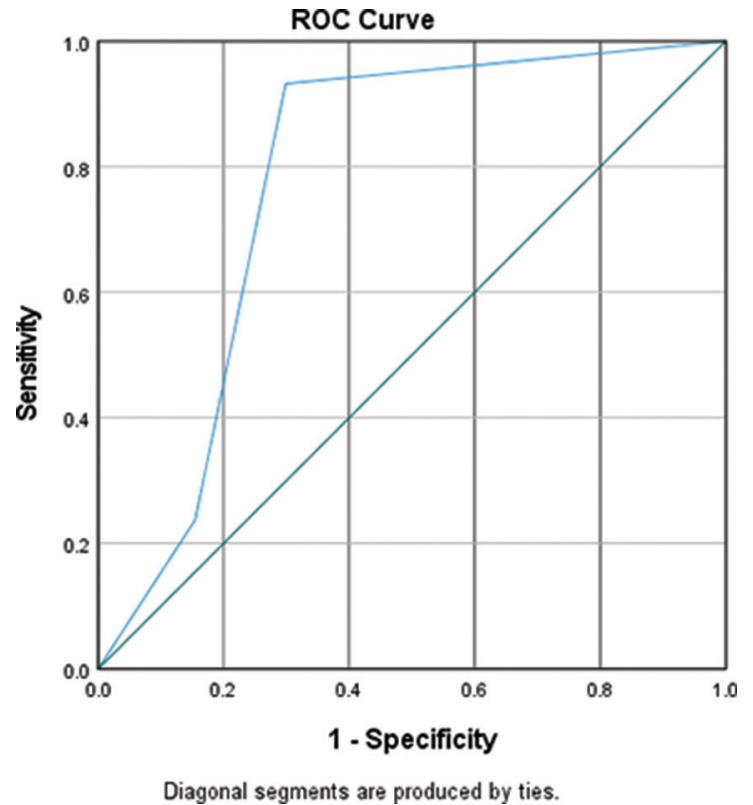

Figure 8. Sensibility and specificity for WL bronchoscopy. WL, white light.

\begin{tabular}{lc}
\hline AF bronchoscopy & Valid N (listwise) \\
\hline Positive $^{a}$ & 84 \\
Negative & 72 \\
\hline
\end{tabular}

Larger values of the test result variable(s) indicate stronger evidence for a positive actual state.

a. The positive actual state is Mucosal changes.

\begin{tabular}{cccccc}
\hline & Area under the curve & & \multicolumn{2}{c}{$\begin{array}{c}\text { Asymptomatic 95\% confidence } \\
\text { interval }\end{array}$} \\
\cline { 1 - 1 } \cline { 5 - 6 } \cline { 5 - 6 } Area & Std. error & Asymptotic sig. & & Lower bound & Upper bound \\
\hline 0.846 & 0.036 & 0.000 & & 0.777 & 0.916 \\
\hline
\end{tabular}

The test result variable(s): Biopsy has at least one tie between the positive actual state group and the negative actual state group. Statistics may be biased.

a. Under the nonparametric assumption.

b. Null hypothesis: true area $=0.5$.

\begin{tabular}{lc}
\hline \multicolumn{2}{c}{ Case processing summary } \\
\hline WL bronchoscopy & Valid N (listwise) \\
\hline Positive $^{a}$ & 59 \\
Negative & 97 \\
\hline
\end{tabular}

Larger values of the test result variable(s) indicate stronger evidence for a positive actual state. a. The positive actual state is Mucosal changes.

\begin{tabular}{cccccc}
\hline & Area under the curve & & \multicolumn{2}{c}{$\begin{array}{c}\text { Asymptomatic 95\% confidence } \\
\text { interval }\end{array}$} \\
\cline { 1 - 1 } \cline { 5 - 6 } \cline { 5 - 6 } Area & Std. error ${ }^{\mathrm{a}}$ & Asymptotic sig. & & Lower bound & Upper bound \\
\hline 0.780 & 0.038 & 0.000 & & 0.705 & 0.855 \\
\hline
\end{tabular}

The test result variable(s): Biopsy has at least one tie between the positive actual state group and the negative actual state group. Statistics may be biased.

a. Under the nonparametric assumption.

b. Null hypothesis: true area $=0.5$.

- Of all patients included in the study with positive biopsies for tumor cells, the most common histopathological type was ADK, $(16.7 \%, n-26)$ followed by squamous $(12.8 \%$, $n-20)$ and microcellular $(5.8 \%, n-9)$. The rest of the histopathological types are moderate dysplasia, severe dysplasia and tuberculosis (TB), (6\%,n-1 for each) Figure 9.

- Regarding the gender distribution of each histopathological type: for males, the squamous $(9.6 \%, n-15)$ type predominates followed by $\operatorname{ADK}(5.8 \%, n-9)$ and on the third microcellular $(3.8 \%, n-6)$. For females, the weight is reversed for the first two places as follows: ADK $(10.9 \%, n-17)$, squamous $(3.2 \%, n-5)$ and microcellular $(2 \%, n-3)$. Figure 10.

- It should be noted that dysplasias (moderate and severe) and TB were found in female gender. These cases are not statistically significant in our study and studies are needed to demonstrate whether preneoplastic mucosal changes have a slower course in females and thus could be detected by bronchoscopy.

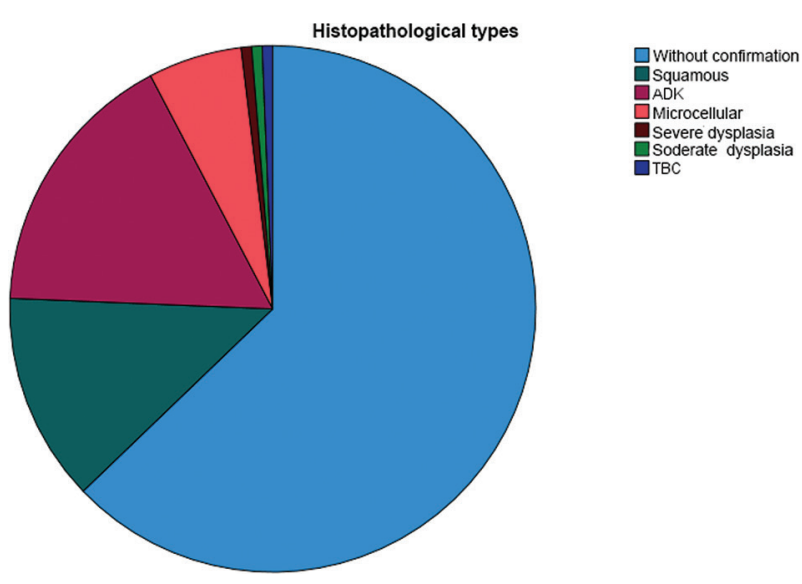

Figure 9. Patients distribution by histopathological types. 


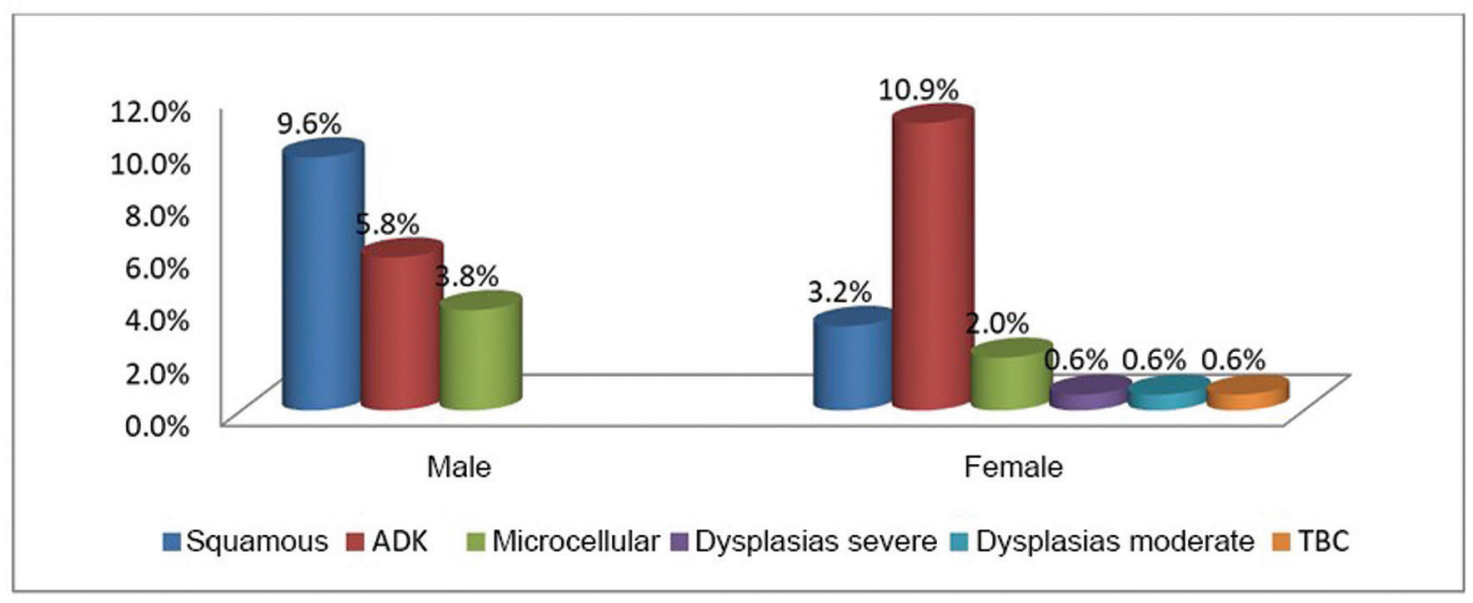

Figure 10. Gender distribution by histopathological types.

\section{Discussions}

Chronic inflammation of the bronchial mucosa can induce the appearance of dysplastic lesions and these can evolve - over a variable period of time - to preneoplastic changes and even broncho-pulmonary neoplasm.

There are few studies in the literature that follow preneoplastic mucosal changes. The present study provides important data on the condition of the bronchial mucosa, studied in both white and blue light. Thus, suspiciously neoplastic mucosal changes in blue light were seen in $15 \%$ of the analysed cases, where examination in WL did not describe changes.

Although mucosal changes were more common in AF than $\mathrm{WL}$, the degree of tumour confirmation was higher in patients examined in WL $(69.49 \%, n-41)$ than those examined in AF $(61.9 \%, n-52)$. This is essential for the study because patients without tumour confirmation but still with mucosal changes, examined in AF had different cell types on histopathological examination than tumour cells (e.g. inflammatory cells). The lack of histopathological confirmation may be due to the presence of only inflammatory changes or an increased inflammation/infiltration ratio. Thus AF examination raises high suspicion of a local preneoplastic process, even in the absence of tumour-modified cells. Moreover, the suspicion of an early preneoplastic process must be thought of after discussing another cause of false-positive results (chronic inflammation or granulomatous processes, local mechanical aggression including recent biopsy). The importance of this data lies in the fact that minimal mucosa changes in AF are an alarm signal for monitoring these lesions. There is a study that analysed the minimal mucosa changes in AF and that advances the idea that this type of lesions can be considered markers for LC (16).
There are recent studies that analysed the other causes for the low specificity of the methods, such as benign lesions, oral anticoagulant treatment, ingestion of photosensitising grugs in the last 3 months and local chemotherapy in the last 6 months (17). However, these records are in favour of the safe use of AF examination, especially when this method is used in combination with the standard light examination. The concomitant use - at the same examination - of both types of lights (standard and blue) increases both specificity and sensitivity of the method (18). The usefulness of AF bronchoscopy is certain and the specificity and sensitivity of the method have been studied for few decades. It is used for diagnosis, monitoring of preneoplastic lesions and setting resection limits, and there are ongoing studies to improve the method. In Romania, the present study is among the first to propose this analysis.

\section{Conclusions}

Lung cancer is a disease with increased incidence in the general population, being resources consuming and, early diagnosis can decrease mortality and increase quality of life. Inflammatory or infectious disease of the broncho-pulmonary tract must generate screening methods for the diagnosis of LC. If we note from studies that mucosal changes progress to neoplasia within a maximum of 15 years, it becomes important to monitor a patient who is at a risk of developing LC. This would allow us to detect small mucosal lesions early and the patient would benefit from rapid treatment and a high life expectancy.

AF bronchoscopy has proven to be a useful method in the early diagnosis of neoplastic lesions and should be used 
in the screening of patients at risk for the development of this type of neoplasia. The high mortality rate is because many patients receive this diagnosis when the disease is so advanced that they can no longer benefit from treatment with curative intent.

Early diagnosis of LC thus becomes very important for rapid access to treatment, decreased mortality and increased quality of life.

The present study aims to bring to the fore the importance of early detection of LC, using a relatively new diagnostic method - AF bronchoscopy. It is a new study for pulmonology in Romania, the results of which could have long-term implications both in terms of the evolution of the incidence of lung neoplasia and the decrease of costs related to investigations of advanced cancer and oncological treatment.

\section{Ethical approval}

Inform consent was obtained from the patients in order to participate to the study and write the article.

\section{Conflict of interest}

The authors have no conflicts of interest.

\section{References}

1. Siegel RL, Miller KD, Jemal A. Cancer statistics, 2018. CA Cancer J Clin. 2018;68(1): 7-30.

2. Bray F, Ferlay J, Soerjomataram I, Siegel LR, Torre LA, Jemal A. Global Cancer Statistics 2018: GLOBOCAN Estimates of Incidence and Mortality Worldwide for 36 Cancers în 185 Countries. CA: Cancer J Clin. 2018;68(6): 394-424.

3. Siegel RL, Miller KD, Jemal A. Cancer statistics, 2020. CA: Cancer J Clin. 2020;70(1): 7-30. Available from: doi:10.3322/caac.21590.

4. Blandin Knight S, Crosbie PA, Balata H, Chudziak J, Hussell T, Dive $C$. Progress and prospects of early detection în lung cancer. Open Biol. 2017;7(9): 170070.

5. Couraud S, Zalcman G, Milleron B, Morin F, Souquet PJ. Lung cancer in never smokers-a review. Eur J Cancer. 2012;48(9): 1299-1311. Available from: doi:10.1016/j.ejca.2012.03.007.

6. Tang MS, Wu XR, Lee HW, Xia Y, Deng FM, Moreira AL, et al. Electronic cigarette smoke induces lung adenocarcinoma and bladder urothelial hyperplasia in mice. Proc Natl Acad Sci USA. 2019;116(43): 21727-21731.
7. Badescu C, Ulmeanu R, Endoscopic methods of early diagnosis of bronchial-pulmonary neoplasm. Pneumologia Magazine. 2017; 66(4): 203-208.

8. Sarkar S, Parrish S, Aboudara M, Krimsky W. Endoscopic imaging technologies in the detection of early stage lung cancer. Pak J Chest Med. 2015; Review article, pjcm.net/index.php/pjcm/ article/view/88.

9. Zheng X, Xiong H, Li Y, Han B, Sun J. Application of quantitative autofluorescence bronchoscopy image analysis method in identifing bronchopulmonary cancer. Technol Cancer Res Treat. 2017;16(4): 482-487.

10. Nakajima T, Yasufuku K. Early lung cancer: Methods for detection. Clin Chest Med. 2013;34(3): 373-383.

11. Kakinuma R, Muramatsu Y, Yamamichi J, Gomi S, Oubel E, Moriyama N. Evaluation of the $95 \%$ limits of agreement of the volumes of 5-year clinically stable solid nodules for the development of a follow-up system for indeterminate solid nodules în CT lung cancer screening. J Thorac Dis. 2018;10(1): 175-189.

12. Ishizumi T, McWilliams A, MacAulay C, Gazdor A, Lam S. Natural history of bronchial preinvasive lesions. Cancer Metastasis Rev. 2010;29(1): 5-14. Available from: doi:10.1007/s10555010-9214-7.

13. Sun S, Yang Y, Chen M, Wang L, Pan H, Zhang X, et al. Comparison of autofluorescence and whith light bronchoscopies performed with Evis Exera Spectrum for the detection of bronchial cancers: A meta-analysis. Transl Lung Cancer Res. 2020;9(1): 23-32.

14. British Thoracic Society guideline for diagnostic flexible bronchoscopy în adults, BTS guidelines, 2020. brit-thoracic.org.uk./ quality-improvement/guidelines/lung-cancer/

15. He Q, Wang Q, Wu Q, Feng J, Cao J, Chen BY. Value of autofluorescence imaging videobronchoscopy în detecting lung cancers and precancerous lesions: A review. Resp Care. 2013;58: 2150-2159.

16. von Boerdonk RAA, Smesseim I, Heideman DAM, Coupe VM, Tio D, Grunberg K, et al. Close surveillance with long-term follow-up of subjects with preinvasive endobronchial lesions. Am J Respir Crit Care Med. 2015; 192(12): 1483-1489.

17. Zheng X, Xiong H, Li Y, Han B, Sun J. Application of quantitative autofluorescence bronchoscopy image analysis method în identifying bronchopulmonary cancer. Technol Cancer Res Treat. 2017;16: 482-487.

18. Sun S, Yang $Y$, Chen M, Wang L, Pan H, Zhang $X$, et al. Comparison of the autofluorescence and white light bronchoscopies performed with the Evis Lucera Spectrum for the detection of bronchial cancers: A meta-analysis. Transl Lung Cancer Res 2020;9(1): 23-32. Available from: doi:10.21037 tlcr.2020.01.04. 